\title{
Prescribers and Naloxone Pharmacy Claims
}

\author{
Rosanna Smart, $P h D^{7}$, Caroline K. Geiger, $B A^{2}$, Christopher M. Jones, PharmD, $M P H^{3}$, \\ and Bradley D. Stein, $P h D^{1,4}$
}

'RAND Corporation, 1776 Main Street, Santa Monica, CA, USA; ${ }^{2}$ Harvard University, Cambridge, USA; ${ }^{3}$ Centers for Disease Control and Prevention, Atlanta, USA; ${ }^{4}$ University of Pittsburgh School of Medicine, Pittsburgh, USA.

J Gen Intern Med 35(8):2475

DOI: $10.1007 / \mathrm{s} 11606-020-05791-5$

(c) Society of General Internal Medicine 2020

$\mathrm{W}$ e appreciate the response from Truong, Patil, and Rich to our study regarding retail pharmacy naloxone prescriptions ${ }^{1}$ and thank them for highlighting the importance of patient and caregiver education for individuals receiving naloxone. While naloxone is generally considered a safe medication, like almost all medications, there are risks of unintended adverse consequences if not used as intended. It is essential that prescribers educate patients and caregivers regarding the circumstances when naloxone should be administered, and the procedures for administering it, when writing a naloxone prescription. In addition, since nearly all states have laws or policies that allow individuals to obtain naloxone from a pharmacist without a prescription from a physician, pharmacists also play a critical role in counseling patients and caregivers regarding the circumstances when naloxone should be administered and proper procedures for administration. ${ }^{2}$

We do note that many individuals seeking naloxone from pharmacies may receive such education from opioid education and naloxone distribution (OEND) programs, but we suspect that the populations served by OEND programs, which commonly also provide naloxone, may have only modest overlap with the population obtaining naloxone from pharmacies. ${ }^{3}$ As a result, pharmacy-dispensed naloxone is likely best viewed as occurring in tandem with OEND program-distributed naloxone, and pharmacists should not assume that individuals obtaining naloxone have been educated about its use.

As Truong, Patil, and Rich observe, naloxone's life-saving effects cannot be understated, and pharmacy-dispensed naloxone is an important component in increasing the availability and use of naloxone to reverse opioid overdoses. It is inherent that both prescribers and pharmacists strive to ensure that individuals obtaining naloxone understand when it should be used, how to administer it, and effects commonly seen after its use.

Corresponding Author: Rosanna Smart, PhD; RAND Corporation1776 Main Street, Santa Monica, CA 90407-2138, USA (e-mail: rsmart@rand.org).

\section{REFERENCES}

1. Smart R, Geiger CK, Jones CM, Stein BD. An Observational Study of Retail Pharmacy Naloxone Prescriptions: Differences Across Provider Specialties and Patient Populations. J Gen Intern Med. 2019.

2. Thakur T, Frey M, Chewning B. Pharmacist roles, training, and perceived barriers in naloxone dispensing: A systematic review. J Am Pharm Assoc (2003). 2020;60(1):178-94.

3. Zaller ND, Yokell MA, Green TC, Gaggin J, Case P. The feasibility of pharmacy-based naloxone distribution interventions: a qualitative study with injection drug users and pharmacy staff in Rhode Island. Subst Use Misuse. 2013;48(8):590-9.

Publisher's Note: Springer Nature remains neutral with regard to jurisdictional claims in published maps and institutional affiliations.

Published online March 24, 2020 